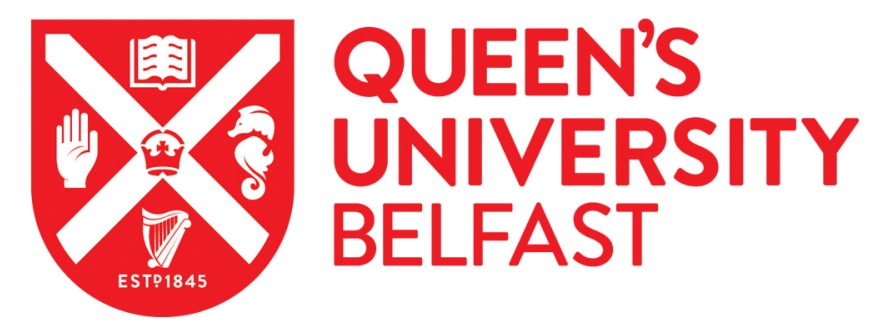

\title{
Bullying Experiences of Child and Adolescent Mental Health Service- users: A Pilot Survey
}

Dyer, K., \& Teggart, T. (2007). Bullying Experiences of Child and Adolescent Mental Health Service-users: A Pilot Survey. Child Care in Practice, 13(4), 351-365. https://doi.org/10.1080/13575270701488733

\author{
Published in: \\ Child Care in Practice
}

\section{Document Version:}

Peer reviewed version

\section{Queen's University Belfast - Research Portal:}

Link to publication record in Queen's University Belfast Research Portal

\author{
Publisher rights \\ Copyright 2007 Taylor \& Francis \\ This is an Accepted Manuscript of an article published by Taylor \& Francis in Child Care in Practice on 13 Aug 2007, available online: \\ http://www.tandfonline.com/doi/abs/10.1080/13575270701488733
}

\section{General rights}

Copyright for the publications made accessible via the Queen's University Belfast Research Portal is retained by the author(s) and / or other copyright owners and it is a condition of accessing these publications that users recognise and abide by the legal requirements associated with these rights.

Take down policy

The Research Portal is Queen's institutional repository that provides access to Queen's research output. Every effort has been made to ensure that content in the Research Portal does not infringe any person's rights, or applicable UK laws. If you discover content in the Research Portal that you believe breaches copyright or violates any law, please contact openaccess@qub.ac.uk. 


\section{Title}

Bullying experiences of child and adolescent mental health service-users: A pilot survey

\section{Date of submission}

08.03.07

\section{Authors}

Kevin Dyer ${ }^{1}$

Tom Teggart ${ }^{2}$

\section{Designation of authors}

${ }^{1}$ Trainee Clinical Psychologist, DClinPsych Course, Queen’s University Belfast

${ }^{2}$ Consultant Clinical Psychologist, Child and Family Clinic, Craigavon and Banbridge HSS Trust

Word count

4,507 words

\section{Mailing address}

Child and Family Clinic, Bocombra Lodge, Bocombra, 2 Old Lurgan Road, BT63 $5 S G$

\section{Email address:}

kdyer01@qub.ac.uk 


\section{Title}

Bullying experiences of child and adolescent mental health service-users: A pilot survey 


\section{Abstract}

Victims and perpetrators of bullying experience a variety of psychological problems. The aim of the current pilot study was to explore the bullying experiences of Child and Adolescent Mental Health (CAMH) service-users. The investigation was conducted as a cross-sectional survey at a community-based specialist CAMH service. A modified version of the Revised Olweus (1996) Bully/Victim Questionnaire was used to assess bullying experiences. Participants comprised an opportunity sample of 26 adolescent male and female CAMH service-users. Results indicated that $61.5 \%$ of participants reported being bullied. Clear links were made between being bullied and the mental health of participants, with $62.5 \%$ of bullied participants reporting that being bullied was a 'Moderately important - Very important' reason for their attendance at the CAMH service. Therapists at the CAMH service made appropriate enquiries about young people being victims of bullying, but more enquiries could be made about young peoples' experiences as perpetrators. Service-users favoured therapist-led bullying interventions such as assertiveness training; therapy and/or psychological coping strategies; and social skills training. These findings underline the need for ecological approaches to dealing with bullying, and suggest that CAMH services could play an important role in establishing and supporting such interventions. 


\section{Introduction}

In recent years, the growing evidence base linking bullying to mental health difficulties has engendered a climate of change in both governmental and societal attitudes to bullying. Child and Adolescent Mental Health (CAMH) services are at the centre of such issues with service-users who are likely to experience bullying as both perpetrators and victims.

Bullying has been defined as “...deliberately hurtful behaviour, repeated over a period of time, where it is difficult for the victim to defend him or herself.” (Department of Education, 1999; p.41). Implicit in this definition is that any behaviour deemed hurtful is considered bullying, including actions as diverse as physical violence, name-calling, and social exclusion. Both children and adolescents are classified in terms of their bullying behaviours as 'bullies', 'victims' and 'bully/victims' (i.e. experience bullying both as bullies and victims) (Olweus, 1986). Bullying occurs less frequently during adolescence than in earlier childhood, but adolescent bullying often has a greater long-term impact on victims (Eslea \& Rees, 2001).

In Northern Ireland, the prevalence of adolescent bullying is markedly higher than in other areas of the UK and Ireland. Whitney \& Smith (1993) conducted a bullying survey of schools in England, reporting a prevalence rate of 14\% for 'victims' of postprimary school bullying and 7\% for 'bullies'. In a nationwide study comprising 20,442 pupils and 531 schools from the Republic of Ireland, O’Moore, et al. (1997) categorised $16 \%$ of second level pupils (i.e. 11 - 18 years old) as 'victims' of bullying, $15 \%$ as 'bullies' and $4 \%$ as 'bully/victims'. Alarmingly, however, Collins et 
al. (2002) reported 30\% of Northern Ireland post-primary pupils were 'victims' of bullying, 29\% were 'bullies', and 12\% were 'bully/victims'.

There have been no formal explanations for the elevated level of bullying within Northern Ireland, although general theoretical understanding of bullying is also limited. Swearer \& Doll (2001) pooled a number of research findings to provide an ecological perspective on bullying based on Bronfenbrenner’s (1977) ecosystem. Intraspsychic predisposing factors to engaging in bullying behaviour include cognitive inflexibility; a belief structure that endorses aggressive strategies to solve conflicts; and an unempathetic, impulsive and domineering personality style (Olweus, 1997). These personal characteristics are mediated by familial and peer contributions such as privation, modelling, and observation of rewarded bullying behaviour (Olweus, 1993; Smith \& Myron-Wilson, 1998). Wider ecosystem influences on bullying include a culture of indifferent acceptance to reports of bullying experiences in schools and communities as well as undeveloped anti-bullying policies and interventions in these locations (Swearer \& Doll, 2001).

In Northern Ireland, a social context exists where the use of violence is familiar and associated with the outplaying of political and religious differences. Such aggressive problem-engagement within this local ecosystem could be linked to similar interpersonal conflict resolution strategies used by child bullies in this society. Furthermore, exposure to “Troubles”-related trauma has been linked to childhood psychological difficulties such as post-traumatic stress and aggressive behaviour (Stewart \& Thomson, 2005). 


\section{Bullying and mental health}

Bullying experiences have been shown to evoke a number of emotional states including anger, frustration, sadness, anxiety and guilt (James et al., 2003; Luis, 2004; Menesini et al., 2003). They have also been associated with more enduring difficulties such as low self-esteem, insomnia, anxiety disorders, depression, attention deficit and hyperactivity disorder (ADHD), somatization, physical health problems, antisocial behaviour, self-harm, suicidal ideation, and attempted suicide (Davies \& Cunningham, 1999; Ireland, 2005; Kumpulainen et al., 2001; Mills et al., 2004; Olweus, 1999; Rigby, 1998; Solberg \& Olweus, 2003).

With such a multitude of psychological and health correlates, it might appear that bullying has general non-specific relationships with psychological and physical wellbeing. However, several prominent trends have emerged from within this melange of research. Investigations using prospective designs highlighted that being a 'victim' of bullying is a direct antecedent to the development of emotional problems and poor social relationships (Bond et al., 2001). Moreover, a comprehensive meta-analysis of 20 years' research on psychological health and bullying revealed that the predominant psychological difficulty associated with being a 'victim' of bullying was depression (Mean $r=0.45$; Hawker \& Boulton, 2000). Other studies have also shown that certain psychological difficulties increase the vulnerability of adolescents in becoming both ‘bullies’ and ‘victims’ (e.g. ADHD; Kumpulainen et al., 2001).

A large proportion of children who have experienced bullying come into contact with mental health services. Kumpulainen et al. (2001) found that $44 \%$ of 'bully/victims', 
$42 \%$ of 'bullies', and $24 \%$ of 'victims' had had contact with mental health professionals compared to $13 \%$ of controls. In a sample of 52 adolescents from a psychiatric outpatient service in England, Salmon et al. (2000) reported that 27\% of participants had been bullied. Authors have also commented that in adolescents where bullying is the central issue, the problem is sometimes hidden behind a secondary complaint such as school refusal or social anxiety (Luis, 2004)

\section{Rationale for current study}

The previous literature review highlights that bullying research is very much in its infancy in Northern Ireland, despite bullying manifesting as a prevalent problem in the region with clear links to mental health difficulties. More worryingly, a high proportion of bullies and victims are likely to be in contact with CAMH services. Some of these children may present with common complaints such as school refusal when the critical underlying, unexplored source of their psychological difficulties could be bullying. Nonetheless, no investigation has systematically examined the bullying experiences of CAMH service-users and explored the potential bullying interventions this service could provide for both bullies and victims. The latter is particularly relevant as the majority of anti-bullying protocols are school-based or regulated by outside agencies (Olweus, 1993).

The present pilot study aimed to examine bullying in a CAMH setting, with a particular emphasis on the experiences of service-users who are victims of bullying. The specific aims of this investigation were: 
1. To explore the nature and extent of bullying experienced by service-users of a CAMH service

2. To examine the relationship between service-user bullying experiences and their mental health difficulties

3. To evaluate the effectiveness of a CAMH service in meeting the needs of service-users with regard to bullying

4. To gain service-user perspectives on the usefulness of potential bullying interventions 


\section{Method}

\section{Participants}

The investigation was conducted as a cross-sectional pilot survey at a communitybased specialist CAMH service in Northern Ireland. Participant inclusion criteria were 1) aged 12 - 17 years old; and 2) service-user of the CAMH service. The sole exclusion criterion was 1) diagnosis of learning disability. Participants were recruited over a three-month period via opportunity sampling. This yielded an overall sample of 26 CAMH service-users (18 male and 8 female) aged $12-17$ years old.

\section{Measures}

Bullying was assessed using a modified version of the Revised Olweus (1996) Bully/Victim Questionnaire. The Revised Olweus (1996) Bully/Victim Questionnaire is considered the 'gold standard' for assessing bullying prevalence rates (e.g. Collins et al., 2002; O’Moore et al., 1997). It is a 39-item self-report measure with questions pertaining to both 'bully' and 'victim' experiences at school that have occurred “in the past couple of months”.

In terms of psychometric properties, Olweus (2002) reported that combinations of Bully/Victim Questionnaire items reflecting 'victim' behaviours and 'bully' behaviours yielded internal consistencies of 0.8 or greater. The validity of participant self-reports of bullying has also been supported. Olweus (1994) quoted correlations of $0.4-0.6$ between self-reports of bullying experiences and independent peer ratings. Bendixen and Olweus (1999) found significant positive correlations between the Olweus Bully/Victim Questionnaire 'victim’ behaviour items and a separate peer 
rejection scale, as well as between 'bully' behaviour items and independent measures of antisocial behaviour.

Despite its established utility, the Olweus measure focuses exclusively on school bullying and lacks items addressing bullying experiences outside school. Furthermore, the present pilot study was primarily concerned with victim experiences rather than bully experiences because of its limited sample size. Consequently, eighteen original questionnaire items were replaced with nineteen ad hoc items constructed for the purposes of this study. The items selected for omission pertained to aspects of bullying that were less relevant to the aims of the current study (e.g. school location of bullying, bully experiences). The removal of Bully/Victim Questionnaire items does not compromise the psychometric integrity of the measure because question responses are examined individually and are not totalled to form an overall scale.

New items added to the questionnaire assessed topics related to the research aims, namely: 1) the nature of bullying experiences; 2) the psychological consequences of bullying experiences; 3) the effectiveness of the CAMH service in meeting the needs of service-users with regard to bullying; and 4) service-user perspectives on potential bullying interventions. It must be acknowledged that, despite the advantage of incorporating such items, none of these new questions were assessed in terms of reliability and validity. Their inclusion produced a 40-item modified version of the original questionnaire. Each questionnaire item represented a separate variable for analysis. 


\section{Procedure}

All service-users with an upcoming appointment at the CAMH service and who met the inclusion/exclusion criteria were sent information about the bullying study. Prospective participants and their parent/guardians were provided with reply slips in this information pack that they could return if they did not wish to participate in the survey.

Service-users who did not return these reply slips were approached at their next clinic appointment and asked to take part in the investigation. Informed consent was obtained from both the participant and a parent/guardian. Participants were given the Revised Olweus (1996) Bully/Victim Questionnaire as well as instructions for its completion. They were also directed to complete the questionnaire in their own time and return the form either by post or at their next clinic appointment. 


\section{Results}

Questionnaire return rate and item selection for analysis

An accurate record of the overall frequency of service-users approached to take part in the investigation, and the reasons of non-participating service-users for declining participation, was unobtainable due to therapist time constraints during data collection. Forty-one questionnaires were administered to service-users, with 26 participants returning their questionnaires. This yielded a return rate of $63.4 \%$

\section{Bullying experiences of CAMH service-users}

Two questionnaire items were used to determine if a participant had been bullied: one standard item from the Revised Olweus (1996) Bully/Victim Questionnaire ("How often have you been bullied at school in the past couple of months?") and an ad hoc item added to the questionnaire by the present authors ("How often have you been bullied in the area where you live in the past couple of months?"). Participants who endorsed "it has only happened once or twice" or a response option of greater frequency (e.g. "several times a week") in either of these items were deemed to have been bullied at the respective location. Figure 1 illustrates that $30.8 \%$ of participants (8 service-users) reported being bullied in the area where they live and $57.7 \%$ of participants (15 service-users) had been bullied at school. Overall, 61.5\% of participants (16 service-users) reported being bullied either at school or in the area where they live at least once or twice over the past couple of months. This combined group were collectively referred to as 'bullied participants' in subsequent analyses.

$<$ Insert Fig. 1 about here $>$ 
Table 1 presents the types of bullying experienced by the 16 'bullied participants' in order of frequency. All bullied participants (100\%) had experienced verbal aggression in the form of generic name-calling/teasing. Name-calling based on race/colour and religion was less common with $37.5 \%$ (6 service-users) and $18.7 \%$ of bullied participants (3 service-users) reporting these forms of bullying respectively.

$<$ Insert Table 1 about here $>$

Relationship between bullying and CAMH service-user mental health difficulties

Questionnaire items examining the link between service-user bullying experiences and their mental health difficulties are depicted graphically in Fig. 2. Each mental health item was carefully worded to ensure ease of understanding among the adolescent sample. For example, 'Thoughts of self-harm' was written as "Have you ever thought about hurting yourself because of being bullied?”.

One item in this section of the questionnaire asked participants "How important is being bullied as a reason for your attendance at the clinic?" . In response to this question, $62.5 \%$ of bullied participants rated being bullied as a 'Moderately important - Very important' reason for their attendance at the CAMH service. The most frequently endorsed problems as a result of bullying were withdrawal from activities and difficulties going to school (i.e. $62.5 \%$ of bullied participants; 11 service-users).

<Insert Fig. 2 about here $>$ 
Effectiveness of a CAMH service with regard to bullying

Fig. 3 contains participant responses to questionnaire items pertaining to CAMH service effectiveness with regard to bullying. $60 \%$ (9/15 bullied participants) of respondents reported that their CAMH therapists had provided 'A good deal - Much' help with being bullied. As regards bullying enquiries, 75\% of bullied participants (12 service-users) and $26.9 \%$ of the overall sample (7 service-users) had been asked if they had been bullied and if they had bullied others respectively.

\section{$<$ Insert Fig. 3 about here $>$}

Service-user perspectives on bullying interventions

Service-users were asked to rank eight different types of bullying intervention in terms of their perceived helpfulness. As with questionnaire items relating to mental health, the descriptions of bullying interventions were simplified for ease of understanding. For example, ‘social skills training' was described as “For someone to teach you skills on how to talk to people and possibly make friends”.

Table 2 contains the median ranks provided by the overall sample for the eight possible types of bullying intervention. It should be noted that a higher rank is represented as a lower value in the table because of the rating scale used in the questionnaire (i.e. 1 = most helpful intervention; 8 = least helpful intervention). Friedman test analysis revealed that helpfulness varied significantly across the eight possible interventions $\left(\chi^{2}=20.83\right.$; $\left.\mathrm{df}=7 ; \mathrm{p}=0.004\right)$. The two interventions perceived as most helpful were 'assertiveness training' and 'therapy and/or psychological coping strategies'. Other highly-ranked interventions included 'social skills training' 
and 'increased teacher support' with median ranks of 4. The lowest-ranked intervention was ‘conflict resolution', with a median rank of 7.

$<$ Insert Table 2 about here $>$ 


\section{Discussion}

\section{Bullying experiences of CAMH service-users}

Bullying was a significant problem for CAMH service-users, seemingly more so than for the general Northern Ireland population and previous studies conducted in mental health settings (e.g. Salmon et al., 2000). A total of 57.7\% of participants reported being bullied at school in the present investigation whereas $42 \%$ of respondents in the Northern Ireland study reported being bullied in some way at school, either as a ‘bully’ or ‘bully/victim’ (Collins et al., 2002). Importantly, unlike other studies using the Olweus Bully/Victim Questionnaire, this investigation measured bullying in the community as well as school settings, resulting in the frequency of bullied participants to further rise to $61.5 \%$.

It is not clear why such high levels of bullying were reported. Bullying may play a direct role in engendering mental health problems, leading to increased referrals to services (Bond et al., 2001). Alternatively, mental health difficulties may increase the vulnerability of adolescents to being bullied (Kumpulainen et al., 2001). Regardless of how it comes about, the high level of bullying reported by service-users is disturbing.

The type of bullying experienced by participants was largely concordant with reports from bullying victims in other studies (e.g. Collins et al., 2002; O’Moore, et al., 1997). Verbal aggression in the form of name-calling and teasing was most common, with social exclusion also figuring prominently. Physical aggression (e.g. hitting, kicking) and sectarian insults were less common. Considering the political situation in Northern Ireland, this may seem surprising. In fact, more participants reported namecalling with reference to race and colour (38.5\%) than religion (18.7\%). It may be that 
the 'peace process' in Northern Ireland has engendered a softening of sectarian attitudes among adolescents. In the absence of evidence for this, however, it may be more likely that the level of sectarian bullying reported is related to continuing religious division. Many communities and the majority of schools in Northern Ireland are segregated by religion, meaning that some adolescents may not have enough contact with members of another religion for sectarian abuse to be consistently experienced. Moreover, students of integrated schools who have more contact with other religions and reduced ‘intergroup anxiety’ are less likely to engage in this form of prejudicial bullying (Hewstone et al., 2005).

One further alarming conclusion that could be drawn from these findings is that the increased racial bullying reported is indicative of the escalating levels of racial tension and harassment observed in Northern Ireland society (Jarman, 2003). Certainly, recent research has indicated that two-thirds of minority ethnic school children in Northern Ireland have experienced racial abuse (Save the Children, 2002).

\section{Relationship between bullying and CAMH service-user mental health difficulties}

The clearest suggestion of a link between bullying and the mental health of serviceusers in the present study was that $62.5 \%$ of bullied participants rated being bullied as a 'Moderately important - Very important' reason for their attendance at the CAMH service. It also suggests that, although bullying might be the central issue for many adolescents, it may not be overtly articulated as such, hidden instead behind more familiar difficulties such as school refusal (Luis, 2004). Bullied participants gave weight to this argument as $62.5 \%$ found it difficult to go to school because of being bullied, and 31.3\% were absent from school because of being bullied. 
Along with difficulties going to school, withdrawal from activities was the most common impact of bullying. In this item, participants endorsed that being bullied stopped them from doing fun activities they would normally do at home or in school. Withdrawal from such activities could be motivated by either anxiety or depression, both of which are common mental health difficulties associated with bullying (Hawker \& Boulton, 2000). Perhaps more worryingly, 50\% of bullied participants reported having thoughts of self-harm, whereas $43.8 \%$ had actively thought about committing suicide because of being bullied. Bullying, therefore, appears to be a significant motivator for self-injurious thoughts, which supports empirical findings of heightened self-harm, suicidal ideation, and suicide attempts in adolescents who have been bullied (Davies and Cunningham, 1999; Mills et al., 2004).

\section{Effectiveness of a CAMH service with regard to bullying}

Overall, when asked about how much help they received from their CAMH therapist about being bullied, 60\% of bullied participants reported 'A good deal' or 'Much', providing a generally positive evaluation of CAMH service efforts to assist with bullying issues. There is a risk that this positive evaluation may be influenced by social biases, as each participant's own therapist administered the questionnaire to them. Although service-users were made aware that their therapist would not have access to their questionnaire data, participants may have still wanted to present a favourable impression of themselves and the CAMH service.

Participant self-reports revealed that, largely, therapists made appropriate bullying enquiries. CAMH therapists asked three quarters of bullied participants if they had 
been bullied. It should be acknowledged, however, that some bullied participants were not asked about their experiences of being bullied. CAMH therapists inquired about bullying others even less frequently, perhaps because the more stigmatizing connotations of the label of 'bully' render the issue more difficult to address. Nonetheless, bullies are at high risk of developing mental health difficulties, with 'bully/victims' representing the most vulnerable group for both adolescent and later adult psychopathology (Kumpulainen et al., 2001). Consequently, it can be argued that therapists should make enquiries with clients about being bullied and bullying others; if not initially, then at some stage in their contact.

Forty-four percent of bullied participants claimed they received information about being bullied from the CAMH service. Although somewhat low, these figures are a good foundation to build upon, considering the ease with which heightened awareness about bullying can be established. One of the key objectives of anti-bullying organisations is to promote public awareness of bullying using a variety of events, such as 'Anti-Bullying Week', and general media (e.g. flyers, TV advertisements; Northern Ireland Anti-Bullying Forum [NIABF], 2005). Resources associated with this campaign are readily available from such organisations. By promoting these materials to adolescents, CAMH services could help raise awareness of bullying among vulnerable service-users and provide them with possible avenues of resolution. Having such material on display in waiting rooms may also communicate to young people that help is available and that the CAMH service may be somewhere to disclose their experiences. 


\section{Service-user perspectives on bullying interventions}

Helpfulness varied significantly across the interventions listed in the questionnaire, indicating that participants were able to discriminate between the eight possible approaches in terms of their utility. Generally, service-users favoured therapist-led interventions such as assertiveness training; therapy and/or psychological coping strategies; and social skills training. Although the role of CAMH services in bullying prevention/intervention has been hitherto unclear, these findings highlight that even standard psychological interventions such as cognitive-behavioural therapy could endow bullying victims with useful coping skills. CAMH services could also provide useful contributions to community views of the bullying problem as well as to both victim and perpetrator interventions at the primary care level and within local communities.

Although provision of information about bullying may be helpful, there is evidence that it is not a sufficient strategy for targeting bullying (Hunt, 2007). The most successful interventions facilitate wider change in the ecosystem of pupils by adopting a "whole school” approach (Olweus, 1993). These interventions cultivate a general shift in school attitudes to bullying and combat this behaviour on multiple levels by providing individual anti-bullying strategies (e.g. assertiveness training for victims); class strategies (e.g. class sanctions on bullying); and school strategies (e.g. clear anti-bullying policy) (McCarthy \& Carr, 2002).

Although "whole school” bullying interventions have been implemented and audited effectively (Olweus, 1993; Smith \& Sharp, 1994), more recent replications have shown modest and inconsistent effects (e.g. Roland, 2000), and they have not been 
systematically applied in Northern Ireland. The young people's favoured interventions in the present study may reflect this situation. They may also reflect wider community views regarding bullying. Unhelpful cultural beliefs that focus on bullying victims 'standing up for themselves' as a means to combat this behaviour are still likely to be prevalent in Northern Ireland. In many ways, these attitudes label the victim as a contributor to the problem through personal deficiency, whereas current understanding regards characteristics of the bully and the surrounding 'ecosystem' as more relevant and influential to bullying behaviour (e.g. Olweus, 1999; Swearer \& Doll, 2001). In spite of this, bullied service-users may see assertiveness training as a means of learning to 'stand up for themselves' in this culturally-privileged manner. Such an interpretation again highlights the need for further dissemination of information on bullying to the public to challenge these established beliefs, and for the widespread implementation of whole-school interventions.

\section{Limitations}

Arguably the biggest limitation of the present study was sample size. Although admittedly a pilot study, the recruitment of 26 adolescents by opportunity sampling limits the representativeness of the sample, and the overall generalisability of findings. Despite providing a wealth of quantitative information about bullying experiences, the simple survey design and low participant numbers precludes drawing clear conclusions about some of the findings (e.g. low rate of sectarian bullying). This is most prominent in the evaluation of CAMH service effectiveness, which should ideally be assessed using a quasi-experimental design comparing levels of bullying and associated psychological difficulties pre- and post-CAMHS intervention. The small sample size also prevents a thorough analysis of other bullying relationships 
such as gender differences, severity of bullying and the nature of both 'bully' and 'victim' experiences. Further investigations are required in CAMH settings with larger sample sizes and more robust methodologies to fully explore these trends.

The absence of information on the number of adolescents approached to take part in the study and service-user reasons for declining participation was also limiting. It could be argued that the high level of bullying reported in the study is a reflection of skewed sampling, in that only service-users who experienced bullying consented to participate in the investigation. However, anecdotal accounts from therapists involved in data collection indicated that many participants actually declined participation because they were being bullied. These service-users found the task of completing a comprehensive questionnaire on bullying too distressing and, while requiring cautious interpretation, it may be that the high frequency of bullying found in the current study represents an underestimation of the problem.

\section{Implications and suggestions for future research}

The high level of bullying reported in this investigation in comparison to regional prevalence rates provides empirical support to long-established anecdotal observations that bullying is a pervasive problem for CAMH service-users as a whole. Mental health difficulties also had a clear relationship with these bullying experiences suggesting a need for formal links between CAMH services, schools, and antibullying agencies (e.g. NIABF).

It may be that CAMH services could optimise their role in tackling bullying by using therapeutic skills to both directly help bullies/victims and co-ordinate anti-bullying 
responses with schools and other organisations. The present study illustrated that a more rigorous assessment of client bullying histories, in terms of both victim and bully roles, is likely to be an important aspect of practice. Moreover, increased promotion of bullying awareness and anti-bullying resources by providing accessible information leaflets, booklets, and posters in clinics as well as high-profile publicising of 'Anti-bullying week' represent simple, yet effective, methods of assisting the antibullying campaign.

A number of avenues are available for potential research in this area. Future studies and anti-bullying protocols should take into account the views of adolescents. Service-users in this investigation gave insight into the possible discrepancy between professional opinions of anti-bullying interventions and adolescent opinions, most notably with regard to conflict resolution. Further development and evaluation of bullying interventions involving CAMH services would also be helpful.

\section{Conclusion}

Bullying is a prevalent problem for CAMH service-users. A higher frequency of bullying was experienced by adolescents in the surveyed population relative to the general population. CAMH service-users reported clear links between these bullying experiences and their mental health difficulties. Although it seems that participants found the CAMH service helpful with regard to bullying, areas for development were identified. These include taking a more active role in addressing bullying by fostering interagency links, promoting bullying awareness, and contributing to bullying interventions. Large-scale investigations should be conducted in this area to expand upon the findings of the present pilot study. 


\section{Acknowledgements}

The authors would like to thank Dr. Noel McCune, Dr. Karen Jack, Dr. Conor McGuckin, Dr. Martin Dempster, and the Northern Ireland Anti-Bullying Forum for their help over the course of this study. Our special gratitude also extends to the therapists at the CAMH service who assisted with data collection, as well as to the service-users involved in the investigation. Ethics approval for the investigation was

gained from the Office for Research Ethics Committees in Northern Ireland (ORECNI). 


\section{References}

Bendixen, M. \& Olweus, D. (1999). Measuring antisocial behavior in early adolescence and adolescence: Psychometric properties and substantive findings. Criminal Behaviour and Mental Health, 9, 323 - 354.

Bond, L., Carlin, J. B., Thomas, L., Rubin, K., \& Patton, G. (2001). Does bullying cause emotional problems? A prospective study of young teenagers. British Medical Journal, 323, $480-484$.

Bronfenbrenner, U. (1977). Toward an experimental ecology of human development. American Psychologist, 32, 513 - 531.

Collins, K., McAleevy, G. \&Adamson, G. (2002). Bullying in schools: A Northern Ireland study. Belfast: Department of Education.

Davies, M. \& Cunningham, G. (1999). Adolescent parasuicide in the Foyle area. Irish Journal of Psychological Medicine, 16(1), 9 - 12.

Department of Education (1999). Report of a survey of provision for Education of Mutual Understanding (EMU) in post-primary schools. Northern Ireland: Department of Education.

Eslea, M. \& Rees, J. (2001). At what age are children most likely to be bullied at school? Aggressive Behavior, 27, 419 - 429. 
Hawker, D. S. J. \& Boulton, M. J. (2000). Twenty years' research on peer victimization and psychosocial maladjustment: A meta-analytic review of crosssectional studies. Journal of Child Psychology and Psychiatry, 41, 441 - 455.

Hewstone, M., Cairns, V. A., Paoline, S., McLernon, F., Crisp, R. \& Niens, U. (2005). Intergroup contact in a divided society: Challenging segregation in Northern Ireland. In D. Abrams, J. M. Marques, \& M. A. Hogg (Eds.), The social psychology of inclsion and exclusion (pp. 265 - 292). Philadelphia: Psychology Press.

Hunt, C. (2007). The effect of an education program on attitudes and beliefs about bullying and bullying behaviour in junior secondary school students. Child and Adolescent Mental Health. 12(1), 21-26

Ireland, J. L. (2005). Psychological health and bullying behaviour among adolescent prisoners: A study of young and juvenile offenders. Journal of Adolescent Health, 36, $236-243$.

James, D.J., Sofroniou, N., \& Lawlor, M. (2003).The response of Irish adolescents to bullying. Irish Journal of Psychology, 24, 22-34.

Jarman, N. (2003). Victims and perpetrators, racism and young people in Northern Ireland. Child Care in Practice, 9(2), 129 - 139. 
Kumpulainen, K., Räsänen, E. \& Puura, K. (2001). Psychiatric disorders and the use of mental health services among children involved in bullying. Aggressive Behavior, 27, $102-110$.

Luis, N. B. (2004). Bullying: Concealed by behavioral and somatic symptoms. Journal of Developmental and Behavioral Pediatrics, 25(5), 348 - 349.

McCarthy, O. \& Carr, A. (2002). Prevention of bullying. In A. Carr (Ed.), Prevention: What works with children an adolescents? A critical review of psychological prevention programmes for children, adolescents, and their families (pp. 205 - 221). London: Routledge.

Menesini, E., Sanchez, V., Fonzi, A., Ortega, R., Costabile, A., Lo Feudo, G. (2003). Moral emotions and bullying. A cross-national comparison of differences between bullies, victims and outsiders. Aggressive Behavior, 29, 515 - 530.

Mills, C., Guerin, S., Daly, I., Lynch, F. \& Fitzpatrick, C. (2005). The Relationship between Bullying, Depression, and Suicidal Thoughts/Behaviours in Irish Adolescents. Irish Journal of Psychological Medicine, 22(1), 112 - 116.

Northern Ireland Anti-bullying Forum (NIABF). (2005). Strategy document 2005 2008. Belfast: NIABF.

Olweus, D. (1986). The Olweus Bully/Victim Questionnaire. Bergen: University of Bergen. 
Olweus, D. (1993). Bullying at school. Cambridge: Blackwell.

Olweus, D. (1994). Annotation: Bullying at school: Basic facts and effects of a school based intervention program. Journal of Child Psychology and Psychiatry, 35, 1171 1190.

Olweus, D. (1996). The Revised Olweus Bully/Victim Questionnaire. Bergen: University of Bergen.

Olweus, D. (1997). Bully/victim problems in school: Knowledge base and an effective intervention program. The Irish Journal of Psychology, 18(2), 170 - 190.

Olweus, D. (1999). Sweden. In P. K. Smith, Y. Morita, J. Junger-Tas, D. Olweus, R. Catalano \& P. Slee (Eds.), The nature of bullying: A cross-national perspective (pp. 7 - 27). London: Routledge.

Olweus, D. (2002). The Revised Olweus Bully/Victim Questionnaire. Bergen: University of Bergen.

O’Moore, A. M., Kirhham, C. \& Smith, M. (1997). Bullying behaviour in Irish schools: A nation-wide study. The Irish Journal of Psychology, 18(2), 141 - 169.

Rigby, K. (1998). Peer relations at school and the health of children. Youth Studies Australia, 17, 13 - 17. 
Roland, E. (2000). Bullying in school: Three national innovations in Norwegian schools in 15 years. Aggressive Behaviour, 26, 135-143

Salmon, G., James, A., Cassidy, E. L. \& Javaloyes, M. A. (2000). Bullying a review: Presentations to an adolescent psychiatric service and within a school for emotionally and behaviourally disturbed children. Clinical Child Psychology and Psychiatry, 5, $563-579$.

Save the Children (2002). Focus on Bullying. Belfast: Save the Children.

Smith, P. K. \& Myron-Wilson, R. (1998). Parenting and school-bullying. Clinical Child Psychology and Psychiatry, 3, 405 - 417.

Smith, P. K. \& Sharp, S. (1994). School bullying: Insights and perspectives. London: Routledge.

Solberg, M. \& Olweus, D. (2003). Prevalence estimation of school bullying with the Olweus Bully/Victim Questionnaire. Aggressive Behavior, 29, 239 - 268.

Stewart, D. \& Thomson, K. (2005). The FACE YOUR FEAR Club: Therapeutic group work with young children as a response to community trauma in Northern Ireland. Child Care in Practice, 11(2), 191 - 209. 
Swearer, S. M. \& Doll, B. (2001). Bullying in schools: An ecological framework. Journal of Emotional Abuse, 2, 7 - 23.

Whitney, I. \& Smith, P. K. (1993). A survey of the nature and extent of bully/victim problems in junior/middle and secondary schools. Educational Research, 35, 3 - 25. 
Fig. 1 Percentage of participants bullied in school and the area where they live

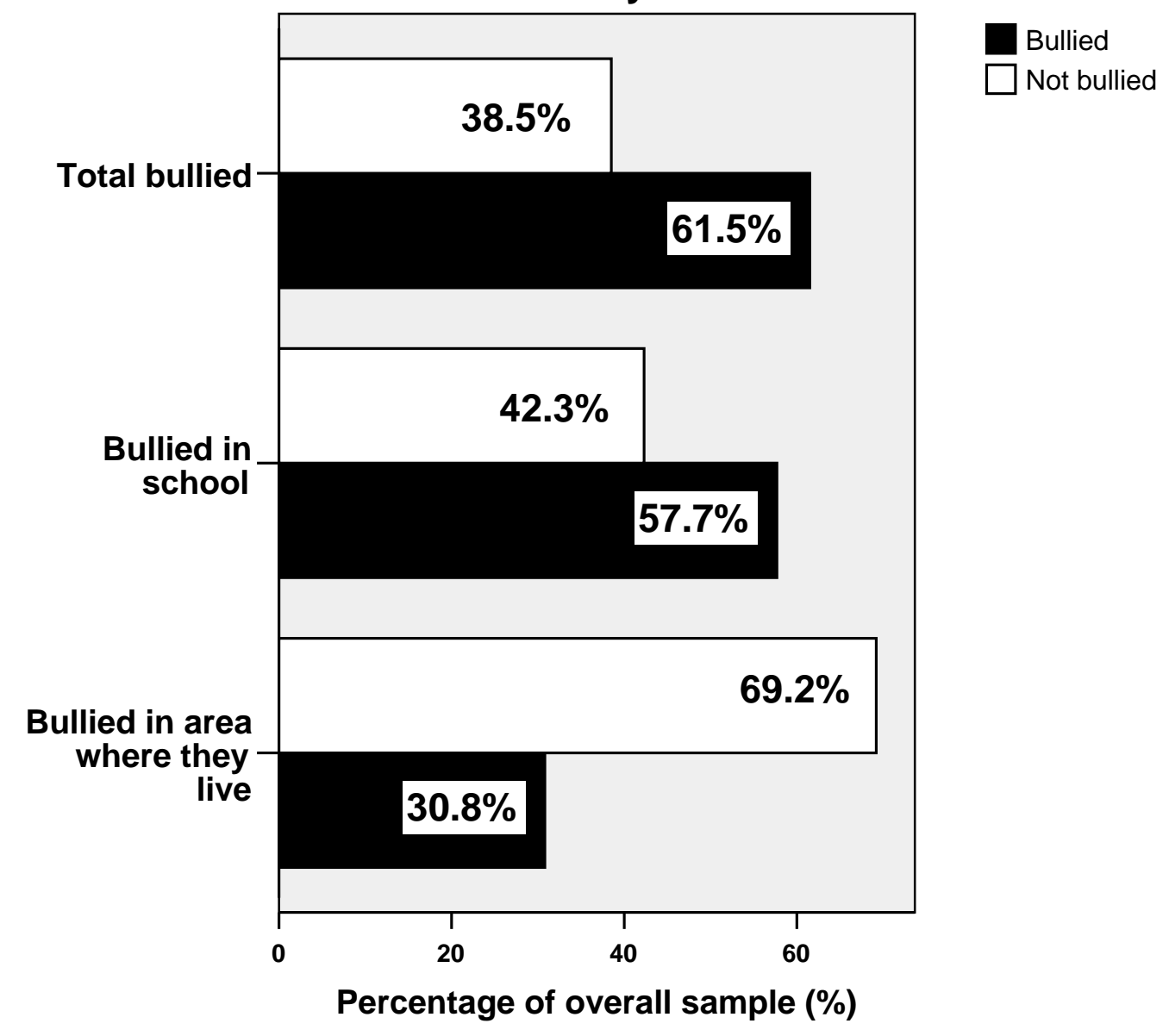


Table 1 Percentage of bullied participants who have experienced different types of bullying

\begin{tabular}{|l|c|}
\hline \multicolumn{1}{|c|}{ Type of bullying } & $\begin{array}{c}\text { Percentage of bullied } \\
\text { participants }\end{array}$ \\
\hline Called mean names, made fun of, or teased & $100 \%$ \\
\hline Excluded from group of friends or ignored & $68.7 \%$ \\
\hline Lies and false rumours told about victim & $68.7 \%$ \\
\hline Called mean names or given gestures with a sexual meaning & $62.5 \%$ \\
\hline Threatened or forced to do things victim did not want to do & $43.8 \%$ \\
\hline Bullied in another way & $43.8 \%$ \\
\hline Called mean names about race or colour & $37.5 \%$ \\
\hline Hit, kicked, pushed or shoved & $25 \%$ \\
\hline Money or belongings stolen/damaged & $25 \%$ \\
\hline Called mean names about religion & $18.7 \%$ \\
\hline
\end{tabular}


Fig. 2 Percentage of bullied participants experiencing psychological difficulties as a result of their bullying experiences

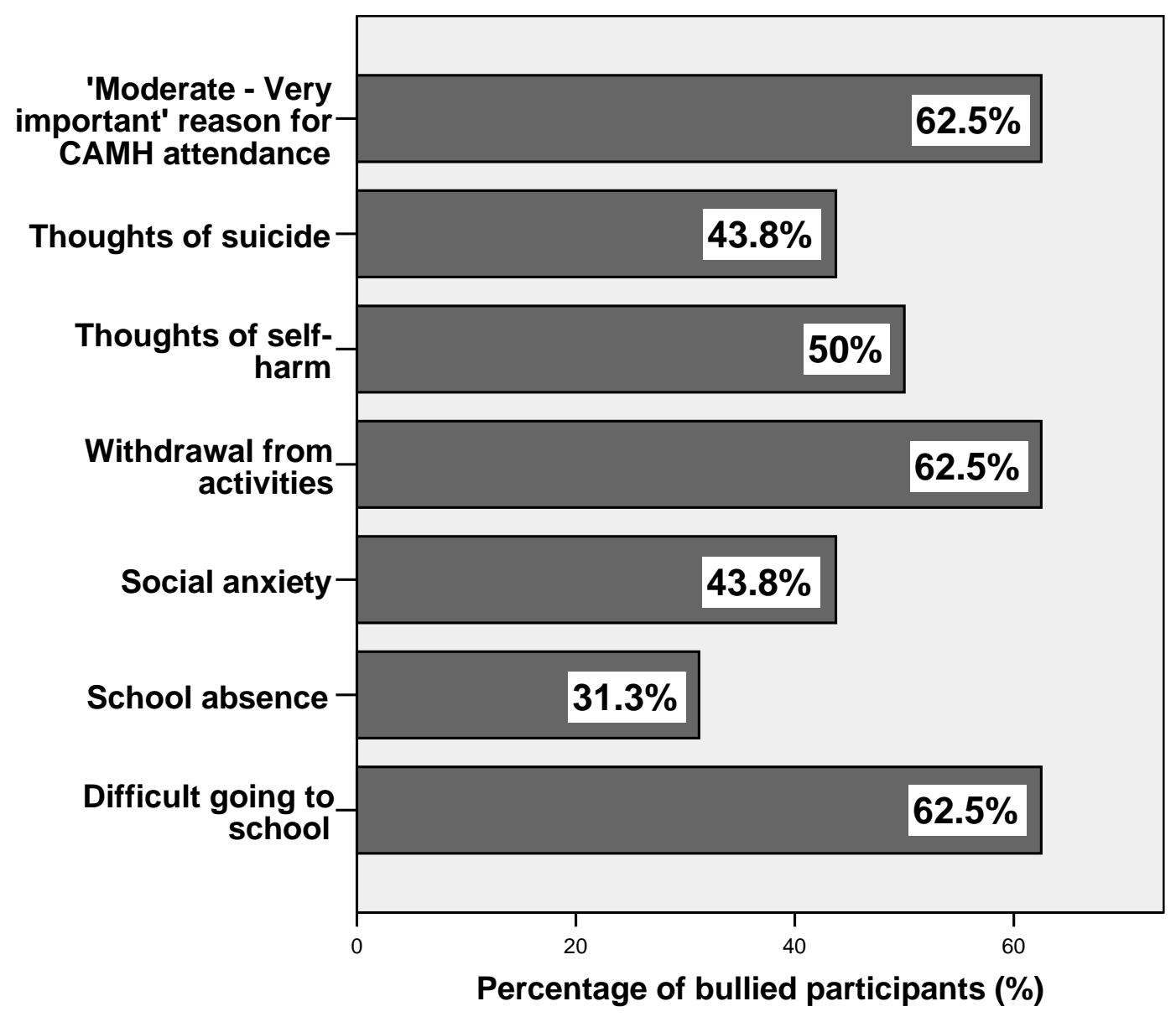


Fig. 3 Participant endorsements on items pertaining to CAMHS effectiveness

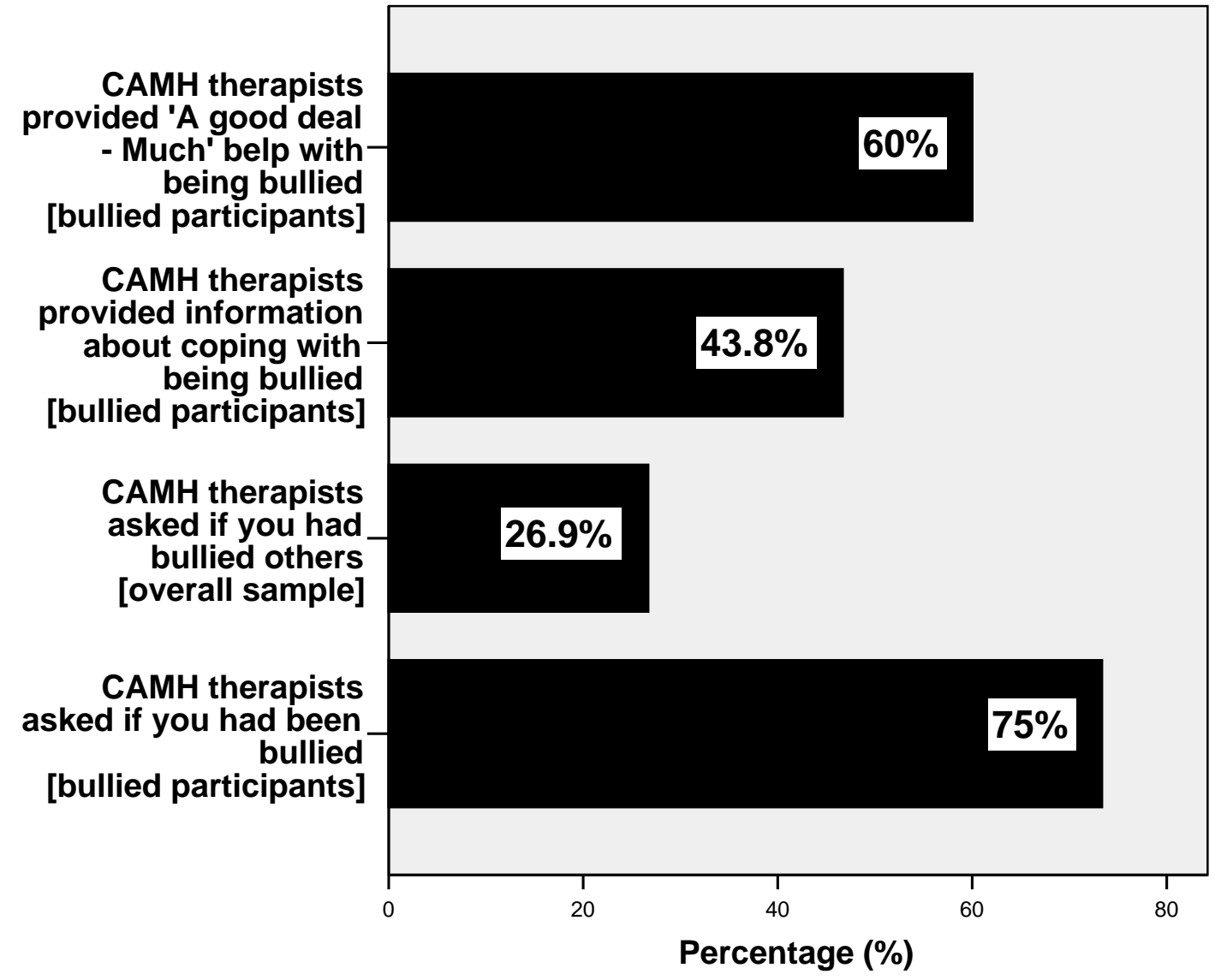


Table 2 Median ranks provided by the overall sample in terms of helpfulness of different types of bullying intervention

\begin{tabular}{|l|c|}
\hline \multicolumn{1}{|c|}{ Type of bullying intervention } & $\begin{array}{c}\text { Median rank of } \\
\text { helpfulness }\end{array}$ \\
\hline Assertiveness training & 3 \\
\hline Therapy and/or psychological coping strategies & 3 \\
\hline Social skills training & 4 \\
\hline Increased teacher support & 5 \\
\hline Increased peer support & 6 \\
\hline Receiving information about coping with being bullied & 6 \\
\hline Telling someone about being bullied and that person acting on it & 7 \\
\hline Conflict resolution & \\
\hline
\end{tabular}

